\title{
Notes \\ Reliability of Fish Size Estimates Obtained From Multibeam Imaging Sonar
}

\author{
Joseph E. Hightower,* Kevin J. Magowan, Lori M. Brown, Dewayne A. Fox \\ J.E. Hightower \\ U.S. Geological Survey, North Carolina Cooperative Fish and Wildlife Research Unit, Department of Biology, \\ North Carolina State University, Raleigh, North Carolina 27695
}

K.J. Magowan

North Carolina Cooperative Fish and Wildlife Research Unit, Department of Biology, North Carolina State University, Raleigh, North Carolina 27695

\section{L.M. Brown, D.A. Fox}

Department of Agriculture and Natural Resources, Delaware State University, Dover, Delaware 19901

\section{Abstract}

Multibeam imaging sonars have considerable potential for use in fisheries surveys because the video-like images are easy to interpret, and they contain information about fish size, shape, and swimming behavior, as well as characteristics of occupied habitats. We examined images obtained using a dual-frequency identification sonar (DIDSON) multibeam sonar for Atlantic sturgeon Acipenser oxyrinchus oxyrinchus, striped bass Morone saxatilis, white perch M. americana, and channel catfish Ictalurus punctatus of known size $(20-141 \mathrm{~cm})$ to determine the reliability of length estimates. For ranges up to $11 \mathrm{~m}$, percent measurement error (sonar estimate - total length)/total length $\times 100$ varied by species but was not related to the fish's range or aspect angle (orientation relative to the sonar beam). Leastsquare mean percent error was significantly different from 0.0 for Atlantic sturgeon $(\bar{x}=-8.34, \mathrm{SE}=2.39)$ and white perch $(\bar{x}=14.48, \mathrm{SE}=3.99)$ but not striped bass $(\bar{x}=3.71, \mathrm{SE}=2.58)$ or channel catfish $(\bar{x}=3.97, \mathrm{SE}=5.16)$. Underestimating lengths of Atlantic sturgeon may be due to difficulty in detecting the snout or the longer dorsal lobe of the heterocercal tail. White perch was the smallest species tested, and it had the largest percent measurement errors (both positive and negative) and the lowest percentage of images classified as good or acceptable. Automated length estimates for the four species using Echoview software varied with position in the view-field. Estimates tended to be low at more extreme azimuthal angles (fish's angle off-axis within the view-field), but mean and maximum estimates were highly correlated with total length. Software estimates also were biased by fish images partially outside the viewfield and when acoustic crosstalk occurred (when a fish perpendicular to the sonar and at relatively close range is detected in the side lobes of adjacent beams). These sources of bias are apparent when files are processed manually and can be filtered out when producing automated software estimates. Multibeam sonar estimates of fish size should be useful for research and management if these potential sources of bias and imprecision are addressed.

Keywords: multibeam; sonar; sturgeon; DIDSON

Received: October 17, 2011; Accepted: November 5, 2012; Published Online Early: November 2012; Published: June 2013

Citation: Hightower JE, Magowan KJ, Brown LM, Fox DA. 2013. Reliability of fish size estimates obtained from multibeam imaging sonar. Journal of Fish and Wildlife Management 4(1):86-96; e1944-687X. doi: 10.3996/102011JFWM-061

Copyright: All material appearing in the Journal of Fish and Wildlife Management is in the public domain and may be reproduced or copied without permission unless specifically noted with the copyright symbol $\odot$. Citation of the source, as given above, is requested.

The findings and conclusions in this article are those of the author(s) and do not necessarily represent the views of the U.S. Fish and Wildlife Service.

* Corresponding author: jhightower@ncsu.edu 


\section{Introduction}

Traditional gear types such as trawls and gill nets have long been used for harvesting fish, but they have many disadvantages when used for surveys. They are difficult to use in deep water and strong currents, or when there are bottom obstructions, even though these obstructions may provide excellent habitat for fish. Areas with frequent boat traffic or where recreational or commercial fishing occurs may be off-limits to sampling with most types of survey gear. In addition, it can be difficult to get authorization for targeted sampling of rare species, and in some cases permits may be required that substantially restrict the amount and types of gear used due to unacceptable mortality of target or nontarget species. When conditions permit the use of traditional methods, the samples are often biased as a measure of abundance or composition in terms of species or sizes. Gill nets are size selective by design, although multipanel nets can reduce this source of bias (Hubert 1983). Trawls select against fish too small to be retained and larger fish that can outswim the trawl (Hayes 1983).

As an alternative, hydroacoustic surveys are relatively unaffected by water depth (range, from a vertically aimed sonar) or current velocity, and they can be used in areas where bottom obstructions might limit the use of nets. The equipment can be used in clear or turbid rivers although high turbidity levels may limit range (Maxwell and Gove 2007). Hydroacoustic methods have the advantage of being noninvasive, so there are no concerns about bycatch or accidental mortalities. Large areas can be mapped using mobile hydroacoustic methods, resulting in good precision and information about the patchiness of fish distributions (Thorne 1983). Fixed-aspect monitoring is often done continuously in rivers to obtain daily estimates of upstream migrants (Daum and Osborne 1998; Ransom et al. 1998; Maxwell and Gove 2007).

The primary disadvantage of traditional hydroacoustic equipment (e.g., split-beam sonar) is that returning echoes may provide little or no information about species, or even size (Thorne 1983; Burwen et al. 2003). This limitation is particularly true for a sonar aimed horizontally and perpendicular to flow, because the intensity of the returning echo (target strength) is related to a fish's size and its aspect angle, that is, its angle with respect to the transducer (Burwen et al. 2007b). Swimming motions cause the aspect angle to vary, resulting in variation in target strength (and estimated fish size). Also, upstream migrants tend to swim close to the bottom, and reverberation from the bottom can bias estimates of fish target strength (Simmonds and MacLennan 2005). Fish location (e.g., in the river channel or water column) can be a clue to species identification but species-level estimates generally rely on complementary sampling using nets or other traditional types of survey gear (Thorne 1983; Daum and Osborne 1998).

Multibeam imaging sonars have the potential to address some of the limitations of earlier generations of hydroacoustic equipment. The multiple beams are able to capture images rapidly, resulting in video-like footage that shows movement and behavior. The video clips are easier to interpret, and they require less training compared with split-beam sonar (Xie et al. 2005; Maxwell and Gove 2007). Images from dual-frequency identification sonar (DIDSON) multibeam sonars (Sound Metrics Corp.; hereafter dual-frequency identification sonar (DIDSON) can provide reliable size information at ranges up to $12 \mathrm{~m}$ for the standard model or $21 \mathrm{~m}$ for the longrange model (Baumgartner et al. 2006; Burwen et al. 2007a, 2010). Identification to species is possible for taxa with unique shapes or fin positions (Baumgartner et al. 2006; Mueller et al. 2008; Crossman et al. 2011).

The objective of this study was to evaluate the reliability of DIDSON length estimates for Atlantic sturgeon Acipenser oxyrinchus oxyrinchus, striped bass Morone saxatilis, white perch M. americana, and channel catfish Ictalurus punctatus of known size. Trials with freeswimming fish that vary in size and shape will aid in judging the extent to which these new methods can replace or complement traditional fisheries survey methods.

\section{Methods}

Pond trials were carried out from October 31 to November 2, 2007, at the Delaware State University Aquaculture Demonstration and Research Facility, in a 0.1-ha aquaculture pond. A block net was used to enclose an area that was slightly larger than the dimensions of the sonar beam. Trials were conducted using a standard DIDSON (model 300) in the highresolution $(1.8-\mathrm{MHz})$ mode, with various combinations of starting distances $(0.42-5.0 \mathrm{~m})$ and lengths $(2.5,5.0$, and $10.0 \mathrm{~m}$ ) for the DIDSON window (field of view). The sonar was tested for proper function by the manufacturer immediately before these trials. The sonar was positioned approximately $0.5 \mathrm{~m}$ above the bottom, and the beam was aimed slightly off bottom (average tilt angle of $1.1^{\circ}$, Table S1, Supplemental Material). DIDSON images showed minor interference from a Biosonics $430-\mathrm{kHz}$ split-beam echosounder that was operated simultaneously to compare fish size information from the two systems (split-beam results not presented here). We used default DIDSON settings for intensity (90 dB), threshold $(15 \mathrm{~dB})$, and receiver gain $(40 \mathrm{~dB})$. Frame rate was set automatically and varied from five to eight frames $/ \mathrm{s}$ (Table S1, Supplemental Material). Fish were identified to species, measured (total length [TL], centimeters) and released into the enclosure either singly or as a pair if differing substantially in size. The net was reset with one or two new fish once an adequate amount of sonar data had been collected.

Thirty-four files representing a range of distances and fish sizes were chosen for analysis (Table S1, Supplemental Material). For each file, four observers independently reviewed a specified range of sonar images (frames) and chose a specific frame for measuring. Observers estimated fish length manually using the fish measuring tool (Mark Fish command, Processing menu) in the Sound Metrics DIDSON Control and Display software version 5.19, without being provided the length or species. 
Table 1. DIDSON files (see Archived Material; from 2007 pond trials at Delaware State University) used to evaluate automated estimates of fish length (TL, total length; FL, fork length) from Echoview software for Atlantic sturgeon Acipenser oxyrinchus oxyrinchus (ATS), striped bass Morone saxatilis (STB), white perch Morone americana (WPC), and channel catfish Ictalurus punctatus (CCAT). For comparison, range, manual estimates of $\mathrm{TL}$, and aspect angle using Sound Metrics software are given for observer 1 .

\begin{tabular}{|c|c|c|c|c|c|c|c|c|c|}
\hline \multirow[b]{2}{*}{ DIDSON data file } & \multirow[b]{2}{*}{ Species } & \multirow[b]{2}{*}{ FL $(\mathbf{c m})$} & \multirow[b]{2}{*}{ TL $(\mathrm{cm})$} & \multirow[b]{2}{*}{$\begin{array}{c}\text { Background } \\
\text { subtraction } \\
\text { frames }\end{array}$} & \multirow[b]{2}{*}{$\begin{array}{l}\text { Window } \\
\text { start } \\
\text { (m) }\end{array}$} & \multirow[b]{2}{*}{$\begin{array}{l}\text { Window } \\
\text { length } \\
\text { (m) }\end{array}$} & \multicolumn{3}{|c|}{ Observer 1} \\
\hline & & & & & & & $\begin{array}{c}\text { Range } \\
\text { (m) }\end{array}$ & $\begin{array}{l}\text { Estimated } \\
\text { TL }(\mathrm{cm})\end{array}$ & $\begin{array}{c}\text { Aspect } \\
\left({ }^{\circ}\right)\end{array}$ \\
\hline 2007-10-31_140001_HF_Clip1.ddf & ATS & 122.0 & 140.5 & $0-58$ & 1.67 & 10.0 & 9.63 & 129.8 & 11.7 \\
\hline 2007-10-31_172000_HF_Clip2.ddf & ATS & 49.6 & 58.7 & $0-53$ & 0.42 & 5.0 & 5.22 & 56.5 & -18.8 \\
\hline 2007-11-01_160549_HF_Clip3.ddf & STB & 37.5 & 39.1 & $0-101$ & 0.42 & 5.0 & 2.67 & 43.9 & 55.9 \\
\hline 2007-11-02_082740_HF_Clip4.ddf & ATS & 110.0 & 120.0 & $0-42$ & 0.42 & 5.0 & 3.66 & 116.7 & 39.0 \\
\hline 2007-11-02_101000_HF_Clip5.ddf & WPC & 21.0 & 22.4 & $0-43$ & 0.42 & 5.0 & 4.77 & 20.1 & 22.8 \\
\hline 2007-11-01_113000_HF_Clip6.ddf & WPC & 20.0 & 21.3 & $65-150$ & 0.42 & 10.0 & 4.26 & 21.5 & 5.2 \\
\hline 2007-11-02_101000_HF_Clip7.ddf & CCAT & 34.4 & 38.1 & $0-60$ & 2.50 & 2.5 & 3.77 & 45.5 & -4.6 \\
\hline 2007-11-01_160549_HF_Clip8.ddf & ATS & 49.4 & 58.6 & $0-45$ & 0.42 & 5.0 & 4.26 & 57.1 & 25.1 \\
\hline 2007-10-31_162000_HF_Clip9.ddf & STB & 39.8 & 41.2 & $50-128$ & 5.00 & 5.0 & 6.49 & 40.3 & 21.3 \\
\hline 2007-11-01_141000_HF_Clip10.ddf & ATS & 53.0 & 62.3 & $0-5$ & 0.42 & 10.0 & 8.25 & 56.7 & 2.0 \\
\hline
\end{tabular}

Following Burwen et al. (2007a), observers attempted to choose a frame for measurement where the full length of the fish was visible. Observers did not use background substraction (an image processing step that can remove a static background) but could choose (for each image) whether to zoom in or use the standard view for measuring. They were asked to rate the quality of each image (poor, marginal, acceptable, or good) and to record the apparent identity (species) of the fish when it seemed to be evident based on shape. Trials were conducted with four species: Atlantic sturgeon $(N=14$ DIDSON files; TL range, $54-141 \mathrm{~cm})$, striped bass $(N=12$, 31-44 cm), white perch $(N=5,20-22 \mathrm{~cm})$, and channel catfish $(N=3,30-38 \mathrm{~cm})$. Each observer participated in the field trials and was therefore aware of the four species that were tested. Despite that knowledge, observers rarely recorded a species identification, and we did not include those results.

We used forward stepwise multiple regression analysis to identify variables affecting percent measurement error: (sonar length $-\mathrm{TL}$ )/TL $\times 100$. Factors considered were species, fish size (TL), observer, window (DIDSON field of view) start distance and window length, range (from target to the sonar when measured), fish aspect (angle of the fish with respect to the sonar; range is -90 [tail toward sonar] to 90 [head toward sonar], 0 is perpendicular to the beam), absolute distance from fish's location where measured to DIDSON focal point, and perceived image quality. Aspect angle is provided by the Sound Metrics software when the fish is measured. We used the auto-focus setting (the likely mode of operation for most users), which sets the focus to be optimal at the center of the selected display range. A Tukey-Kramer honestly significant difference was used to compare least-square mean percent measurement errors among species. A significance level of 0.05 was used for all tests.

For a subset of files (Table 1), we also compared TL with automated length estimates obtained using Echoview software (version 4.60). We used a default analysis pathway that included background subtraction and a
$3 \times 3$ median filter (Myriax 2008). The $3 \times 3$ median filter smoothes the image by replacing each pixel with the median value of it and its eight neighboring pixels. We evaluated two additional filters (dilation and erosion) that further smooth images but found that fish size estimates were either similar to or occasionally much worse than estimates from the default pathway. Final steps in the analysis pathway were to detect fish (abovethreshold clusters of returning echoes, moving in a consistent trajectory) using a multibeam target detection operator and then to remove any detected fish with an estimated length less than $20 \mathrm{~cm}$. This latter step reduced extraneous noise but did not affect our ability to detect fish close in size to the $20-\mathrm{cm}$ threshold. Length estimates were examined for each frame in a fish track and the mean and maximum estimates from a track were compared with the true total lengths using linear regression.

\section{Results}

Fish used in trials ranged from 20 to $140 \mathrm{~cm} \mathrm{TL}$, with 22 of 24 being less than $65 \mathrm{~cm}$ (Table S1, Supplemental Material). The distance from the sonar to measured fish (range of target) varied from 2.2 to $10.8 \mathrm{~m}$. Aspect angle varied from -46.8 to $79.0^{\circ}$. Combining over observers, most images were classified as good (26\%) or acceptable (44\%), with $21 \%$ considered marginal and $9 \%$ poor. As examples, the image in Figure 1a was measured by two observers and both rated it as good, whereas two observers rated the image in Figure $1 \mathrm{~b}$ as acceptable. Two observers measured the image in Figure 1e, and one considered it acceptable and the other rated it as good.

Fish shape and fin positions were much more apparent within a 5-m compared with a 10-m DIDSON window length (Figure 1). For Atlantic sturgeon with TLs of $58 \mathrm{~cm}$ (Figure 1c) and $120 \mathrm{~cm}$ (Figure 1a), body shape and fin positions were readily apparent at a window length of $5 \mathrm{~m}$. Each acoustic pixel in Figures $1 \mathrm{a}$ and $1 \mathrm{c}$ 


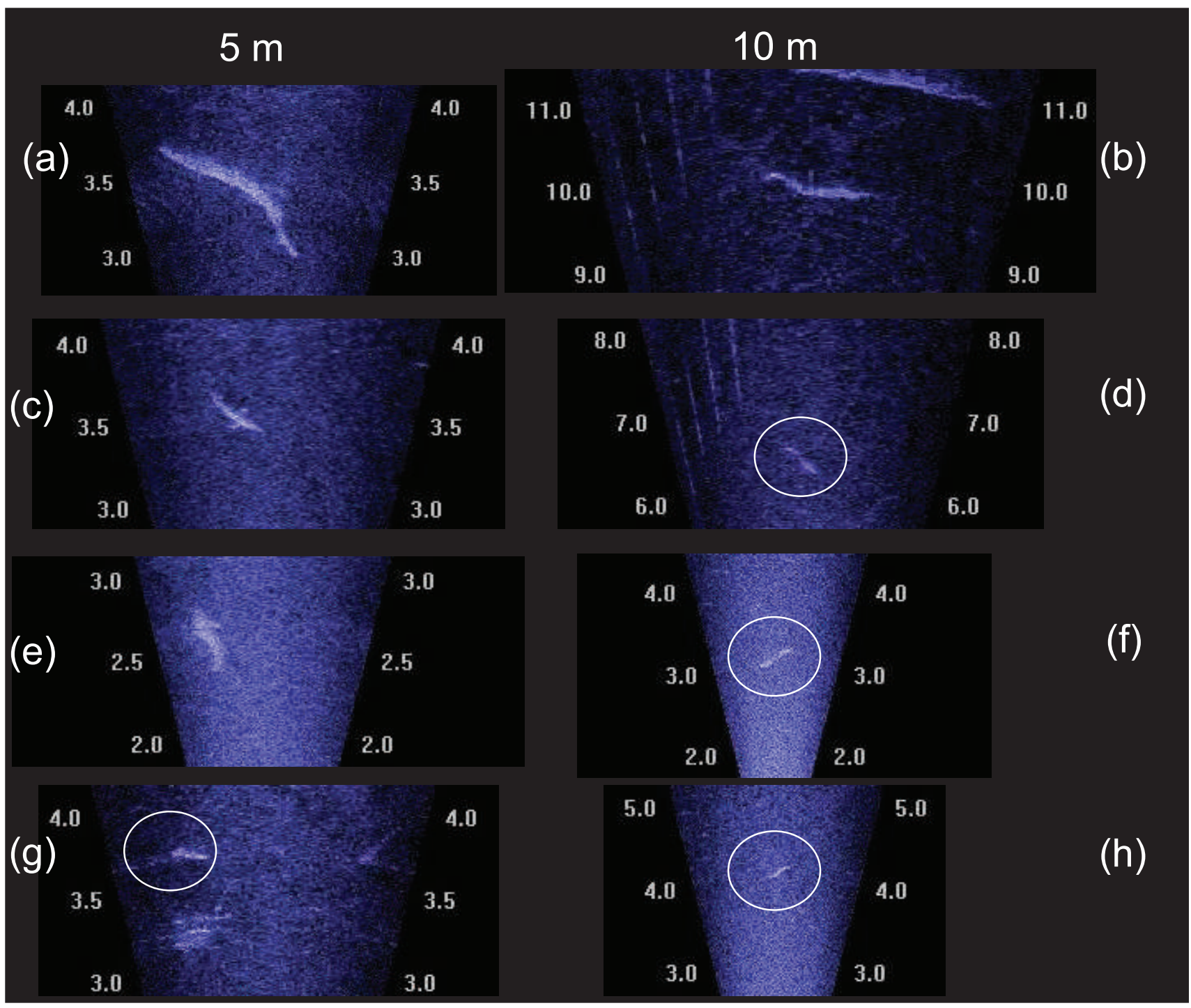

Figure 1. DIDSON images from 2007 pond trials at Delaware State University of Atlantic sturgeon Acipenser oxyrinchus oxyrinchus (a: $110 \mathrm{~cm}$ FL, $120 \mathrm{~cm}$ TL, Video S4, Supplemental Material; b: $122.0 \mathrm{~cm} \mathrm{FL,} 140.5 \mathrm{~cm}$ TL, Video S1, Supplemental Material; c: 48 cm FL, $58 \mathrm{~cm} \mathrm{TL}$; d: $49 \mathrm{~cm} \mathrm{FL,} 58 \mathrm{~cm} \mathrm{TL}$ ), striped bass Morone saxatilis (e: $38 \mathrm{~cm} \mathrm{FL,} 39 \mathrm{~cm} \mathrm{TL}$, Video S3, Supplemental Material; f: $40 \mathrm{~cm} \mathrm{FL,}$ $41 \mathrm{~cm} \mathrm{TL}$ ), and white perch Morone americana (g: $21 \mathrm{~cm} \mathrm{FL,} 22 \mathrm{~cm} \mathrm{TL} ; \mathbf{h}: 21 \mathrm{~cm} \mathrm{FL}, 22 \mathrm{~cm} \mathrm{TL}$ ) at window lengths of $5 \mathrm{~m}$ (left column) and $10 \mathrm{~m}$ (right column). Each panel is a cropped section of a full DIDSON image.

would have a width of approximately $2 \mathrm{~cm}$ (standard DIDSON beam width is range/2/96 beams) so the images contain a fair amount of detail. At a window length of $10 \mathrm{~m}$ (Figure $1 \mathrm{~b}$ ), each acoustic pixel has a width of approximately $5 \mathrm{~cm}$ so the image of a $141-\mathrm{cm}$ TL Atlantic sturgeon was poorly defined. Images of smaller fish (striped bass [Figure 1e], white perch [Figure 1g]) captured the general body shape but would not be useful for identification to species.

Percent error for manual measurements varied significantly due to species $(P<0.001)$ but not fish total length $(P=0.54)$, window starting distance $(P=0.65)$, or length $(P=0.85)$, range $(P=0.27)$, aspect angle $(P=$ $0.60)$, absolute distance from fish's location to focal point $(P=0.62)$, or image quality $(P=0.06)$. Fish total length was a significant factor $(P=0.002)$ if species was not included in the model. The least-square mean percent error differed significantly from zero for Atlantic sturgeon $(-8.34 \%$; 95\% confidence interval $[\mathrm{Cl}],-10.46,-6.21)$ and white perch $(14.48 \% ; 95 \% \mathrm{Cl}, 6.58,22.38)$ but not for striped bass $(3.71 \% ; 95 \% \mathrm{Cl},-1.39,8.81)$ or channel catfish $(3.97 \% ; 95 \% \mathrm{Cl},-6.23,14.17)$. The least-square mean for Atlantic sturgeon differed significantly $(\alpha=$ $0.05)$ from the means for striped bass and white perch. The degree to which DIDSON length estimates were less than true total length seemed to be similar for both size groups of Atlantic sturgeon (Figure 2). Percent measurement errors were similar in magnitude and direction for the similarly sized striped bass and channel catfish but were greatest (both positive and negative) for white perch, the smallest fish tested (Figure 2). Most percent measurement errors (absolute) were less than 20\% (93\% 


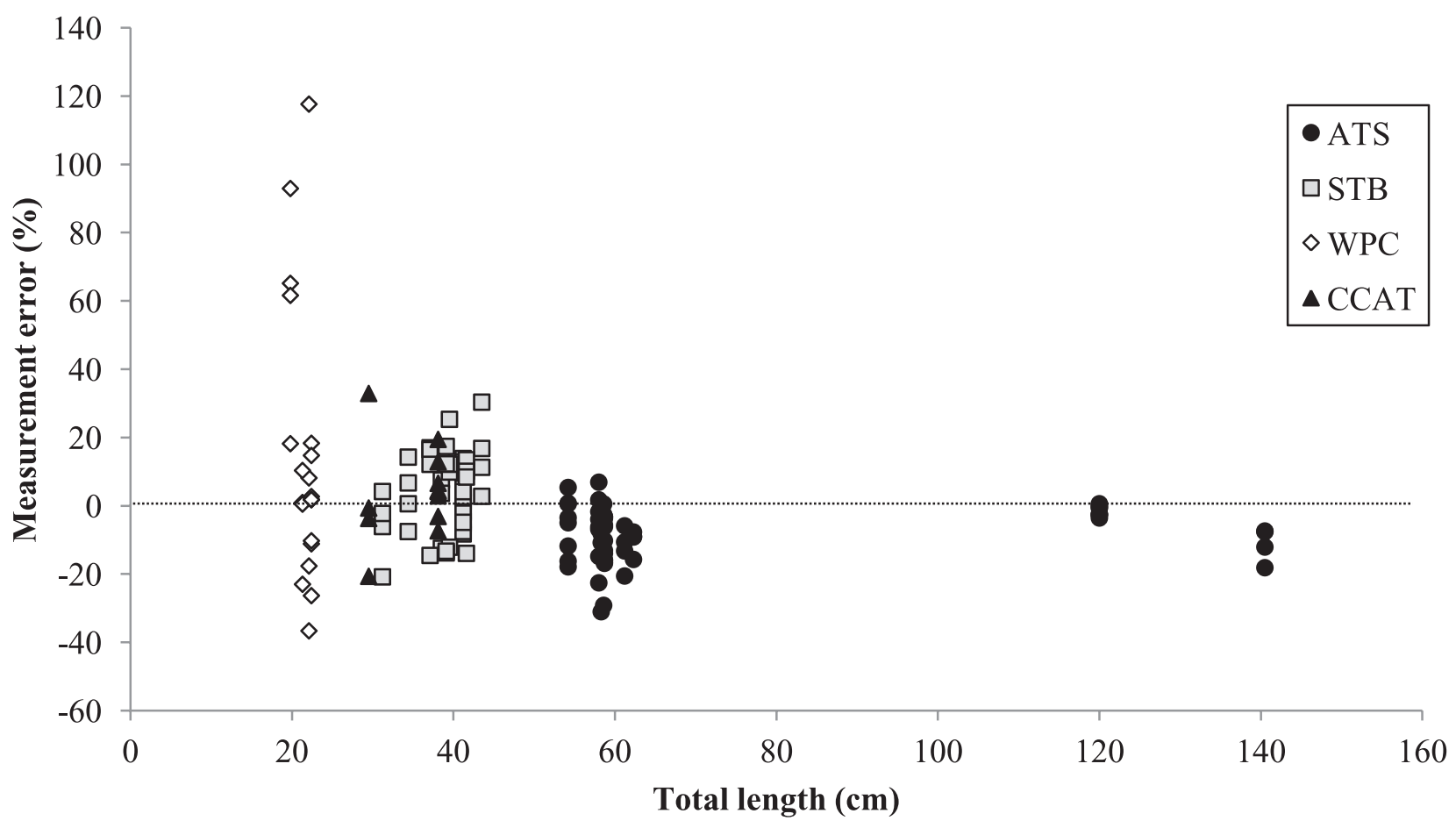

Figure 2. Total length $(\mathrm{cm})$ versus percent measurement error from manual measurement of DIDSON images for Atlantic sturgeon Acipenser oxyrinchus oxyrinchus (ATS), striped bass Morone saxatilis (STB), white perch Morone americana (WPC), and channel catfish Ictalurus punctatus (CCAT), obtained in 2007 pond trials at Delaware State University. Results for the four observers are treated as replicates.

of Atlantic sturgeon estimates, $94 \%$ for striped bass, $83 \%$ for channel catfish) except for white perch (65\%).

Fish total length exhibited a strong linear relationship $(P<0.0001)$ with both the maximum and mean of automated length estimates from Echoview tracks for a subset of fish (Figure 3). The slope relating true TL to the maximum software estimate showed no significant bias (slope $=0.93 ; 95 \% \mathrm{Cl}, 0.66,1.19)$. The slope for the mean software estimate $(0.65 ; 95 \% \mathrm{Cl}, 0.49,0.80)$ showed a significant negative bias, but the predictive equation had a slightly higher $R^{2}$ value (Figure $3 b$ ). The typical pattern was for software estimates to be quite low in the first few frames of a fish track, because of poorer image quality at more extreme azimuthal angles (fish's angle off-axis within the view-field, Figure 4, inset frame 86). Software length estimates improved as fish neared the center of the view-field (Figure 4, inset frames 107, 121), but occasional low estimates were still obtained (Figure 4, inset frame 102). Maximum software estimates were too large in a few cases when acoustic crosstalk occurred (clips 4, 6, and 7). This phenomenon occurs when a highly reflective object (in this case, a fish perpendicular to the sonar and at relatively close range) is detected in the side lobes of adjacent beams (http://www.didson. com/SONAR101/crosstalk.html). Returning echoes from these side lobes create an arc that is readily apparent to an observer but that can cause software length estimates to be too high (Figure 5, frame 78). Another source of error that sometimes occurred in the first or last few frames was when a fish was partially outside the viewfield (Figure 5, frame 47). This type of error would primarily be an issue at close range, and especially for large fish that are a substantial fraction of the view-field.

\section{Discussion}

Our pond trials with free-swimming fish of known size showed moderate error but no significant bias in DIDSON size estimates for striped bass and channel catfish. There was a significant negative bias in length estimates for Atlantic sturgeon. This result was surprising to us because this was the largest species tested, and images seemed to be of good quality. This bias might be due to the difficulty of detecting the snout or the longer dorsal lobe of the heterocercal tail, although Crossman et al. (2011) obtained reliable estimates of adult white sturgeon Acipenser transmontanus lengths, by using a standard DIDSON in low-frequency mode at ranges up to $20 \mathrm{~m}$. We observed a significant positive bias in length estimates for white perch, although percent measurement errors varied widely in both directions. White perch was the smallest species tested and also the species with the lowest percentage of images classified as good or acceptable. The amount of information contained in a multibeam sonar image is a function of range and fish size (Burwen et al. 2010). For a standard DIDSON in highfrequency mode, an image of a $20-$ or $30-\mathrm{cm}$ fish (e.g., white perch) would be based on only 8-12 beams at $5 \mathrm{~m}$ or 4-6 beams at $10 \mathrm{~m}$.

Overestimates of fish length could be due to a fish's movement during the interval required to construct a DIDSON image (Burwen et al. 2010). Another potential bias is due to the discrete nature of DIDSON length 

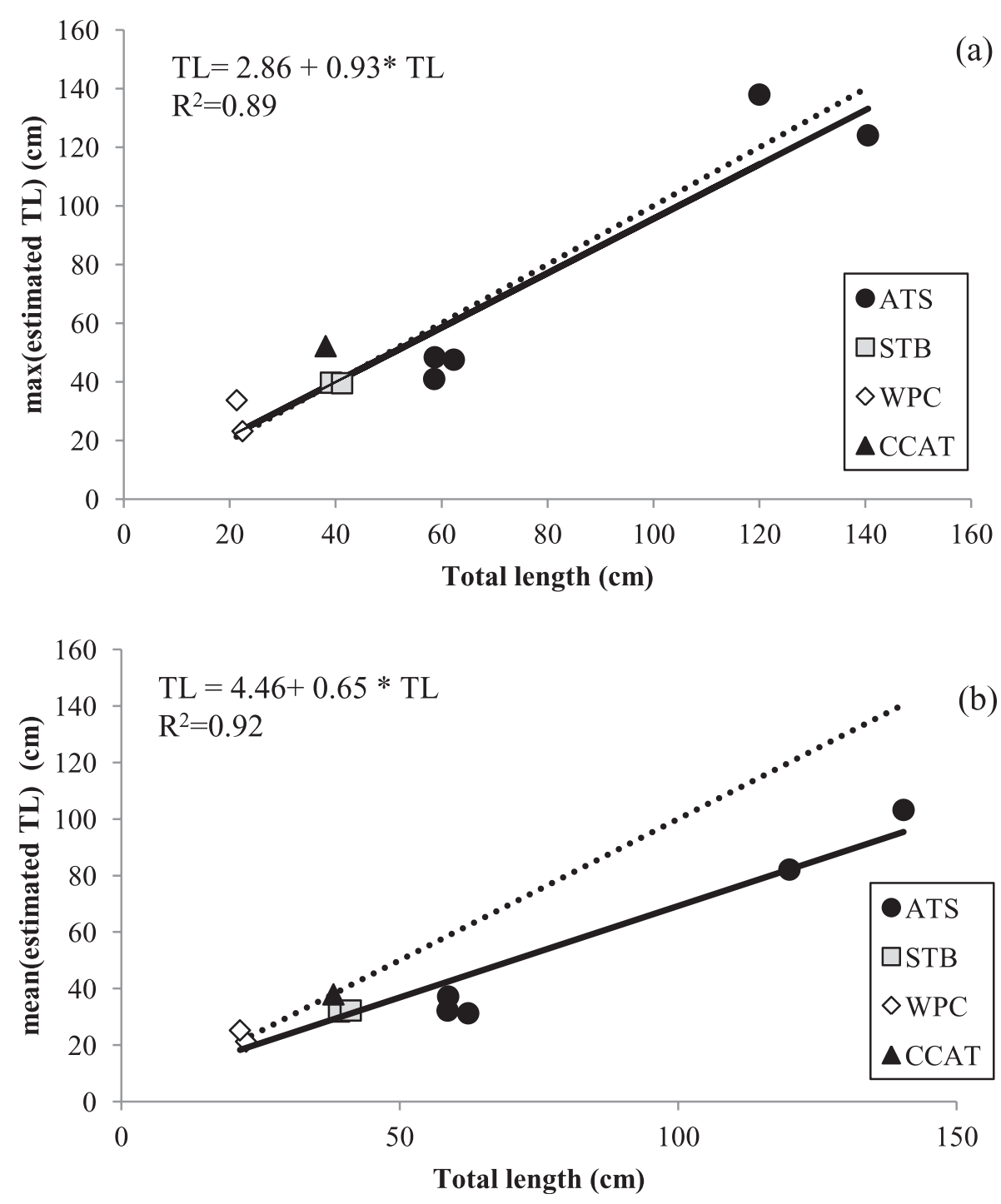

Figure 3. Linear regression analysis of (a) maximum and (b) mean estimated total length from an automated Echoview analysis of DIDSON images comprising a fish track versus measured total length for 10 example DIDSON files (Table 1) for Atlantic sturgeon Acipenser oxyrinchus oxyrinchus (ATS), striped bass Morone saxatilis (STB), white perch Morone americana (WPC), and channel catfish Ictalurus punctatus (CCAT). DIDSON data were obtained in 2007 pond trials at Delaware State University. Dotted lines indicate a 1:1 relationship between estimates and true total lengths.

estimates (Cronkite et al. 2006; Burwen et al. 2007a). DIDSON fish images increase in length by the full width of each beam with a detectable echo, regardless of the fraction of the beam width occupied by the fish. Those errors would be expected to increase with range, although we did not detect a significant range effect over the relatively short range tested. Because these errors are a function of beam width, they would affect percent errors to a greater degree for small fish.

Burwen et al. (2007a) reported substantial positive bias in DIDSON length estimates of tethered Chinook salmon Oncorhynchus tshawytscha and sockeye salmon Oncorhynchus nerka. They did not detect similar bias in their estimates of free-swimming Chinook salmon, coho salmon Oncorhynchus kisutch, pink salmon Oncorhynchus gorbuscha, chum salmon Oncorhynchus keta, and Dolly Varden Salvelinus malma. The difference between study approaches was thought to be due to the unnatural positioning of tethered fish in the center of the beam (Burwen et al. 2007a). Those fish would have been (mostly) perpendicular to the beam and in the innermost sub-beams that have higher sensitivity. Both of these factors would contribute to the positive bias discussed previously. Free-swimming fish would not always have been near the center of the beam or perpendicular to it, so those factors would have tended to reduce DIDSON size estimates (possibly offsetting the positive bias).

We did not detect an effect of range on percent measurement errors. Burwen et al. (2010) found no effect of range on DIDSON estimates of fish length using a long-range DIDSON. Range would more likely have a detectable effect in our study if trials at greater distances had been included. However, the standard DIDSON has 


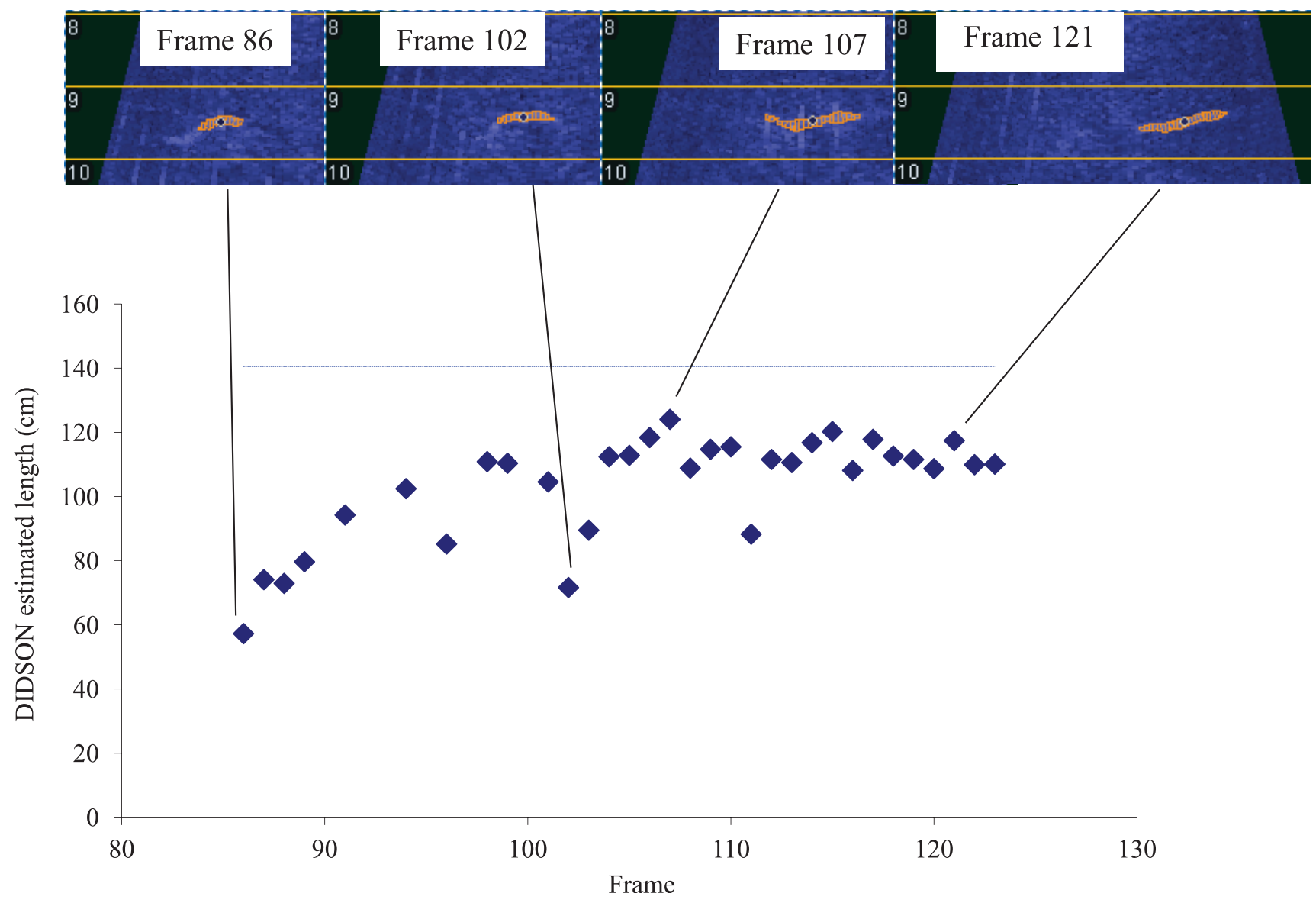

Figure 4. Sonar estimates of total length from an automated Echoview analysis for an Atlantic sturgeon Acipenser oxyrinchus oxyrinchus (dashed line shows TL $140.5 \mathrm{~cm}$ ) by using DIDSON data obtained in 2007 pond trials at Delaware State University. Inset images show, for specific frames, the tracked target as an overlay on the raw DIDSON image.

a limit of $15 \mathrm{~m}$ for the high-frequency setting, so farther ranges would require the low-frequency setting that uses half the beams, resulting in lower image quality. The lack of evidence for a range effect in our trials also could have been due to variation in image quality or to the range of aspect angles that we used, although neither factor was significant in our regression analysis. We also did not detect an effect of the distance from a fish's position (where measured) to the focal point, which ranged from 0.02 to $3.9 \mathrm{~m}$. This factor may be more important when using windows of greater length.

The importance of aspect angle may be underestimated in our study. Most measured images had aspect angles relatively close to 0.0 (quartiles of -5.9 and $24.0^{\circ}$ ) because observers selected what were judged to be the best images for measuring. This factor might be better evaluated using templates (e.g., Langkau et al. 2012) deployed at a specific angles, rather than free-swimming fish. Burwen et al. (2007a) suggested that the fish's orientation (aspect angle) and degree of arching of the body contributed to measurement errors.

Our automated length estimates using Echoview software showed consistent trends with the fish's position in the view-field. Estimates at more extreme azimuthal angles tended to be low, likely due to the reduced sensitivity of sub-beams farther off the main beam axis. This typically resulted in a low average estimate for the fish track, although the maximum estimate within a track was generally close to the true total length. A similar trend in DIDSON length estimates was observed by Boswell et al. (2008). They suggested that low initial estimates within a fish track may have been due to more extreme aspect angles or to difficulty in detecting the beginning and end of the fish image at more extreme azimuthal angles. This latter issue is illustrated in our Figure 4, frame 86. Our software estimates also were biased by fish images partially outside the view-field and when acoustic crosstalk occurred. These sources of bias are less of a concern for manual measurements because a frame can be selected that shows the fish's full length with good contrast between the fish image and background (Cronkite et al. 2006; Burwen et al. 2007a). An automated approach for avoiding these potential biases would be to include additional filters in the analysis pathway (Aquacoustics 2010). For example, size estimates can be based on the subset of images where the tracked fish is near the center of the sonar beam so as to avoid fish being partially outside the view-field. Images where crosstalk would bias size estimates can be filtered out by excluding images that have an anomalously high estimated length relative to thickness. 


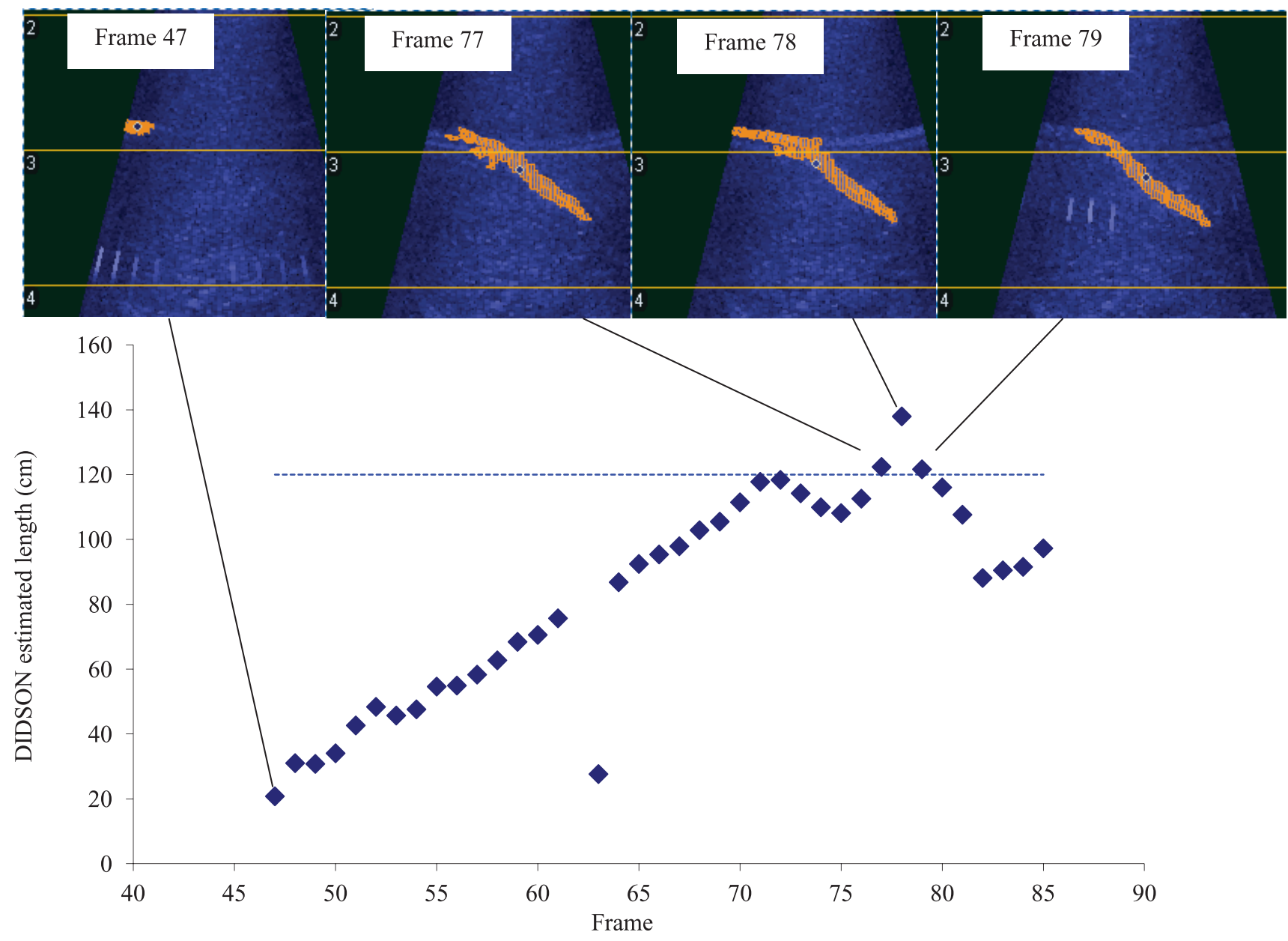

Figure 5. Sonar estimates of total length from an automated Echoview analysis for an Atlantic sturgeon Acipenser oxyrinchus oxyrinchus (dashed line shows TL $120.0 \mathrm{~cm}$ ) by using DIDSON data obtained in 2007 pond trials at Delaware State University. Inset images show, for specific frames, the tracked target as an overlay on the raw DIDSON image.

One approach for reducing the effect of errors due to sonar estimates of length would be to work with averages or to group fish into biologically relevant size categories (e.g., estimates in the size range of blueback herring Alosa aestivalis or white perch $[<30 \mathrm{~cm}]$ versus larger). Burwen et al. (2007a) suggested that the DIDSON had good potential for discriminating among species of different sizes, as long as the species differences were large relative to DIDSON measurement errors. Cronkite et al. (2006) found that frequency distributions were similar for actual lengths and DIDSON estimates for sockeye salmon. They limited their analysis to DIDSON images at ranges of 1-6 $\mathrm{m}$ and only used fish that produced clear images perpendicular to the transducer. The mean of DIDSON length estimates $(59.6 \mathrm{~cm})$ was slightly larger than the mean for measured fish $(58.0 \mathrm{~cm})$; Cronkite et al. (2006) attributed this difference to the discrete nature of DIDSON length estimates.

A practical concern about multibeam imaging sonars is that high-quality images are only obtained at a relatively short range. One approach in riverine studies is to install weirs on both banks to reduce the channel opening to $10 \mathrm{~m}$ or less (Cronkite et al. 2006; Holmes et al. 2006; Kerkvliet et al. 2008). If weirs are not feasible because of currents or depths, another option is to use a midchannel deployment with an alternating sequence of aims to cover more of the channel cross section (D. Degan, Aquacoustics, personal communication). For example, a sonar can be deployed in midchannel and aimed toward alternating banks. The combined set of files could provide high-resolution data for a 20-m section of the channel cross section. Burwen et al. (2010) obtained useful estimates of fish size at ranges to at least $21 \mathrm{~m}$ by using a long-range DIDSON coupled with an ultrahigh-resolution lens. Different lens options can be used to vary the view field and vertical beam height depending on range to be monitored, water depth, and vertical distribution of fish. Fish migrating upstream against strong currents are often found close to the bottom (Daum and Osborne 1998), so a high vertical beam height may not be needed.

Multibeam imaging sonars hold much promise for improving fisheries surveys, but it is important to conduct trials with objects of known size (including fish), to understand the limitations of this new technology. Our percent measurement errors (absolute) were generally less than $20 \%$ except for white perch, the smallest species tested. The potential for bias in future settings will likely 
depend on the size, shape, and species composition of fish to be monitored. The best approach for evaluating the bias would be trials using free-swimming fish combined with measurements of templates at a series of ranges from the sonar. Experiments with templates are a practical option at field sites whereas trials with free-swimming fish are difficult (although see weir trials conducted by Burwen et al. 2007a). The combination of methods should aid in sorting out the importance of physical factors such as range or aspect angle from biological factors such as fish shape or swimming behavior. A multibeam imaging sonar could then be used with confidence to estimate fish size or in mixture models to estimate species composition (e.g., Fleischman and Burwen 2003).

\section{Supplemental Material}

Please note: The Journal of Fish and Wildlife Management is not responsible for the content or functionality of any supplemental material. Queries should be directed to the corresponding author for the article.

Table S1. DIDSON data file characteristics (from 2007 pond trials at Delaware State University). Variables are fork length (FL), total length (TL), fish identifier (FishID), starting range for DIDSON view field (WindowSt), length of DIDSON view field (WindowLen), sonar tilt angle, sonar frame rate (automatically set by sonar control unit), identifier for biologist producing the length estimate (BiolD), frame used to estimate size, range and aspect angle for measured image, and DIDSON length estimate (Est TL).

Found at DOI: http://dx.doi.org/10.3996/102011JFWM-061.S1 (20 KB XLSX).

\section{Archived Material}

Please note: The Journal of Fish and Wildlife Management is not responsible for the content or functionality of any archived material. Queries should be directed to the corresponding author for the article.

To cite this archived material, please cite both the journal article (formatting found in the Abstract section of this article) and the following recommended format for the archived material.

Hightower JE, Magowan KJ, Brown LM, Fox DA. 2013. Data from: Reliability of fish size estimates obtained from multibeam imaging sonar, Journal of Fish and Wildlife Management 4(1):86-96; Archived in Dryad Digital Repository: http://dx.doi.org/10.5061/dryad.h1n02

2007-10-31_140001_HF_Clip1. Video clip created from DIDSON file (from 2007 pond trials at Delaware State University) showing $140.5-\mathrm{cm}$ Atlantic sturgeon Acipenser oxyrinchus oxyrinchus, using a window length of $10 \mathrm{~m}$ (Table 1).

Found at DOI: http://dx.doi.org/10.5061/dryad.h1n02 (9.93 MB DDF).

2007-10-31_172000_HF_Clip2. Video clip created from DIDSON file (from 2007 pond trials at Delaware State University) showing $58.7-\mathrm{cm}$ Atlantic sturgeon Acipenser oxyrinchus oxyrinchus, using a window length of $5 \mathrm{~m}$ (Table 1).
Found at DOI: http://dx.doi.org/10.5061/dryad.h1n02 (11.51 MB DDF).

2007-11-01_160549_HF_Clip3. Video clip created from DIDSON file (from 2007 pond trials at Delaware State University) showing $37.5-\mathrm{cm}$ striped bass Morone saxatilis, using a window length of $5 \mathrm{~m}$ (Table 1).

Found at DOI: http://dx.doi.org/10.5061/dryad.h1n02 (6.23 MB DDF).

2007-11-02_082740_HF_Clip4. Video clip created from DIDSON file (from 2007 pond trials at Delaware State University) showing 110.0-cm Atlantic sturgeon Acipenser oxyrinchus oxyrinchus, using a window length of $5 \mathrm{~m}$ (Table 1).

Found at DOI: http://dx.doi.org/10.5061/dryad.h1n02 (5.68 MB DDF).

2007-11-02_101000_HF_Clip5. Video clip created from DIDSON file (from 2007 pond trials at Delaware State University) showing $22.4-\mathrm{cm}$ white perch Morone americana, using a window length of $5 \mathrm{~m}$ (Table 1).

Found at DOI: http://dx.doi.org/10.5061/dryad.h1n02 (10.03 MB DDF).

2007-11-01_113000_HF_Clip6. Video clip created from DIDSON file showing $21.3-\mathrm{cm}$ white perch Morone americana, using a window length of $10 \mathrm{~m}$ (Table 1).

Found at DOl: http://dx.doi.org/10.5061/dryad.h1n02 (7.46 MB DDF).

2007-11-02_101000_HF_Clip7. Video clip created from DIDSON file (from 2007 pond trials at Delaware State University) showing $38.1-\mathrm{cm}$ channel catfish Ictalurus punctatus, using a window length of $2.5 \mathrm{~m}$ (Table 1).

Found at DOl: http://dx.doi.org/10.5061/dryad.h1n02 (7.31 MB DDF).

2007-11-01_160549_HF_Clip8. Video clip created from DIDSON file (from 2007 pond trials at Delaware State University) showing $58.6-\mathrm{cm}$ Atlantic sturgeon Acipenser oxyrinchus oxyrinchus, using a window length of $5 \mathrm{~m}$ (Table 1).

Found at DOI: http://dx.doi.org/10.5061/dryad.h1n02 (6.62 MB DDF).

2007-10-31_162000_HF_Clip9. Video clip created from DIDSON file (from 2007 pond trials at Delaware State University) showing $41.2-\mathrm{cm}$ striped bass Morone saxatilis, using a window length of $5 \mathrm{~m}$ (Table 1).

Found at DOI: http://dx.doi.org/10.5061/dryad.h1n02 (6.37 MB DDF).

2007-11-01_141000_HF_Clip10. Video clip created from DIDSON file (from 2007 pond trials at Delaware State University) showing $62.3-\mathrm{cm}$ Atlantic sturgeon Acipenser oxyrinchus oxyrinchus, using a window length of $10 \mathrm{~m}$ (Table 1).

Found at DOl: http://dx.doi.org/10.5061/dryad.h1n02 (6.37 MB DDF).

\section{Acknowledgments}

We thank Brian Richardson (MD DNR), the staff at the Patuxent River Chalk Point Generating station, and 
Andrew Lazur (University of Maryland Center for Environmental Science Horn Point Laboratory) for providing the Atlantic sturgeon used in this study. D. Burwen, H. J. Flowers, A. Grote, A.-M Mueller, P. Bettoli, M. W. Waine, G. Zydlewski, the Subject Editor, and an anonymous reviewer provided helpful comments on earlier versions of this manuscript. B. Hanot (Sound Metrics) provided useful information about factors affecting DIDSON images.

The North Carolina Cooperative Fisheries and Wildlife Research Unit is jointly supported by North Carolina State University, North Carolina Wildlife Resources Commission, U.S. Geological Survey, and Wildlife Management Institute.

Any use of trade, product, or firm names is for descriptive purposes only and does not imply endorsement by the U.S. Government.

\section{References}

Aquacoustics. 2010. Semi-automated DIDSON data analysis for the assessment of Kenai chinook salmon. Aquacoustics, Sterling, Alaska. Available: http://www. aquacoustics.com/proj_Didson-automation.html (October 2011).

Baumgartner LJ, Reynoldson N, Cameron L, Stanger J. 2006. Assessment of a Dual-frequency Identification Sonar (DIDSON) for application in fish migration studies. NWS Department of Primary Industries, Narrandera Fisheries Centre, Final Report Series No. 84, Narrandera, New South Wales. Available: http://www.dpi.nsw.gov. au/__data/assets/pdf_file/0009/136665/Output-686_ DIDSON-Report_FORMATTED.pdf (October 2011).

Boswell KM, Wilson MP, Cowan JH Jr. 2008. A semiautomated approach to estimating fish size, abundance, and behavior from dual-frequency identification sonar (DIDSON) data. North American Journal of Fisheries Management 28:799-807.

Burwen DL, Fleischman SJ, Miller JD, Jensen ME. 2003. Time-based signal characteristics as predictors of fish size and species for a side-looking hydroacoustic application in a river. ICES Journal of Marine Science 60:662-668.

Burwen DL, Fleischman SJ, Miller JD. 2007a. Evaluation of a dual-frequency imaging sonar for detecting and estimating the size of migrating salmon. Alaska Department of Fish and Game, Fishery Data Series 0744. Available: http://www.adfg.alaska.gov/FedAidPDFs/ fds07-44.pdf (March 2012).

Burwen DL, Fleischman SJ, Miller JD. 2010. Accuracy and precision of salmon length estimates taken from DIDSON sonar images. Transactions of the American Fisheries Society 139:1306-1314.

Burwen DL, Nealson PA, Fleischman SJ, Mulligan TJ, Horne JK. 2007b. The complexity of narrowband echo envelopes as a function of fish side-aspect angle. ICES Journal of Marine Science 64:1066-1074.

Cronkite GMW, Enzenhofer HJ, Ridley T, Holmes J, Lilja J, Benner K. 2006. Use of high-frequency imaging sonar to estimate adult sockeye salmon escapement in the Horsefly River, British Columbia. Canadian Technical Report of Fisheries and Aquatic Sciences 2647. Available: http://www.dfo-mpo.gc.ca/Library/323344. pdf (March 2012).

Crossman JA, Martel G, Johnson PN, Bray K. 2011. The use of dual-frequency identification sonar (DIDSON) to document white sturgeon activity in the Columbia River, Canada. Journal of Applied Ichthyology 27(Suppl. 2):53-57.

Daum DW, Osborne BM. 1998. Use of fixed-location, splitbeam sonar to describe temporal and spatial patterns of adult fall chum salmon migration in the Chandalar River, Alaska. North American Journal of Fisheries Management 18:477-486.

Fleischman SJ, Burwen DL. 2003. Mixture models for the species apportionment of hydroacoustic data, with echo-envelope length as the discriminatory variable. ICES Journal of Marine Science 60:662-668.

Hayes ML. 1983. Passive capture techniques. Pages 123-145 in Nielsen LA, Johnson DL, editors. Fisheries Techniques. Bethesda, Maryland: American Fisheries Society.

Holmes JA, Cronkite GMW, Enzenhofer HJ, Mulligan TJ. 2006. Accuracy and precision of fish-count data from a "dual-frequency identification sonar" (DIDSON) imaging system. ICES Journal of Marine Science 63: 543555.

Hubert WA. 1983. Passive capture techniques. Pages 95-111 in Nielsen LA, Johnson DL, editors. Fisheries Techniques. Bethesda, Maryland: American Fisheries Society.

Kerkvliet CM, Burwen DL, Begich RN. 2008. Anchor River 2003 and 2004 Chinook salmon and 2004 coho salmon escapement. Alaska Department of Fish and Game, Fishery Data Series No. 08-06. Available: http:// www.adfg.alaska.gov/FedAidpdfs/FDS08-06 (March 2012).

Langkau MC, Balk H, Schmidt MB, Borcherding J. 2012. Can acoustic shadows identify fish species? A novel application of imaging sonar data. Fisheries Management and Ecology 19:313-322.

Maxwell SL, Gove NE. 2007. Assessing a dual-frequency identification sonars' fish-counting accuracy, precision, and turbid river range capability. Journal of the Acoustical Society of America 122:3364-3377.

Mueller A-M, Mulligan T, Withler PK. 2008. Classifying sonar images: can a computer-driven process identify eels? North American Journal of Fisheries Management 28:1876-1886.

Myriax. 2008. Echoview tutorial: introduction to DIDSON data processing. Myriax, Hobart, Tasmania, Australia. Available: http://echoview.com/files/Tutorials/IntroTo DIDSONDataProcessing.exe (September 2011).

Ransom BH, Johnston SV, Steig TW. 1998. Review on monitoring adult salmonid (Oncorhynchus and Salmo spp.) escapement using fixed-location split-beam hydroacoustics. Fisheries Research 35:33-42. 
Simmonds J, MacLennan D. 2005. Fisheries acoustics: theory and practice. 2nd edition. Oxford, UK: Blackwell Science.

Thorne RE. 1983. Hydroacoustics. Pages 239-259 in Nielsen LA, Johnson DL, editors. Fisheries Techniques. Bethesda, Maryland: American Fisheries Society.
Xie Y, Gray AP, Martens FJ, Boffey, JL, Cave JD. 2005. Use of dual-frequency identification sonar to verify salmon flux and to examine fish behaviour in the Fraser River Pacific Salmon Commission Technical Report 16. Available: http://www.psc.org/pubs/psctr16.pdf (March 2012). 